\section{O corpo e a cidade: aproximações e subjetividades}

\author{
Débora S. Allemand, Eduardo Rocha
}

Débora S. Allemand é Mestra em Arquitetura e Urbanismo; Professora na Universidade Federal de Pelotas; deborallemand@hotmail.com

Eduardo Rocha é Doutor em Arquitetura; Professor na Universidade Federal de Pelotas; amigodudu@yahoo.com.br

\section{Resumo}

O ensaio propõe uma revisão de literatura que aproxima os conceitos de espaço, cidade, corpo, capitalismo, experiência e sujeito. Tem como principais referências: Bondía (2002), Deleuze (1992), Deleuze e Guattari (1997), Foucault (1988), Guattari (2003), Harvey (2014), Jacques (2008), Miranda (2008) e Santos (2014). A partir de teorias da filosofia pós-estruturalista, entende-se corpo e cidade como instituições ligadas e em constante troca, visibilizando cultura, cidade e capital como estruturas que cotidianamente reterritorializam os cidadãos. As aproximações concluem que as cidades são importantes espaços de subjetivação e que deveriam ser lugares de construção do conhecimento através da experiência do corpo no espaço público.

Palavras-chave: cidade, corpo-espaço, capitalismo, subjetividade.

\begin{abstract}
The essay proposes a literature review that approaches the concepts of space, city, body, capitalism, experience and subject. Its main references are: Bondía (2002), Deleuze (1992), Deleuze and Guattari (1997), Foucault (1988), Guattari (2003), Harvey (2014), Jacques (2008), Miranda (2008) and Santos (2014). From theories of post-structuralist philosophy, body and city are understood as structures that daily reterritorialize citizens. Approaches conclude that cities are important spaces of subjectivity and that they must be places where knowledge is built, through the experience of the body in public spaces.
\end{abstract}

Keywords: city, body-space, capitalism, subjectivity.

\section{Resumen}

El ensayo propone un repaso de la literatura que se acerca a los conceptos de espacio, ciudad, cuerpo, capitalismo, experiencia y sujeto. Las principales referencias son: Bondía (2002), Deleuze (1992), Deleuze and Guattari (1997), Foucault (1988), Guattari (2003), Harvey (2014), Jacques (2008), Miranda (2008) and Santos (2014). El archivo fue escrito a partir de las teorías de la filosofía posestructuralista, en que se puede comprehender cuerpo y ciudad como instituciones relacionadas y en constante cambio, dando un vistazo a la cultura, ciudad y el capital como estructuras que cotidianamente reterritorializan los ciudadanos. La investigación concluye que las ciudades son espacios importantes de subjetividad y deberían ser sitios de construcción del conocimiento a través de la experiencia del cuerpo en el espacio público.

Palabras-clave: ciudad, cuerpo-espacio, capitalismo, subjetividad.
ALLEMAND, Débora S.; ROCHA, Eduardo. O corpo e a cidade: aproximações e subjetividades. Thésis, Rio de Janeiro, v. 2, n. 4, p. 259276, nov./dez. 2017

data de submissão: 14/10/2016 data de aceite: $07 / 02 / 2017$ 
ste ensaio se propõe a fazer uma breve revisão teórica, principalmente a partir dos estudos pós-estruturalistas, a respeito de sociedade, espaço, tempo, cidade e corpo, buscando compreender como são os sujeitos que agem no mundo atual e que produzem as cidades na contemporaneidade, sendo produzidos por elas também.

O texto percorre uma trajetória de conceitos, iniciando a discussão sobre espaço, tempo e território. Na próxima parte, as questões de corpo, sujeito e as experiências deste corpo na cidade são o foco, até chegar à ideia de corpo-espaço, compreendendo que a cidade é um elemento importante de subjetivação para os corpos.

Os cidadãos da cidade estão em constante troca e reconstituição, a partir do contexto em que residem. A maioria dos habitantes das cidades não tem experiência urbana, apesar de passar grande parte do dia no trânsito indo de casa para o trabalho e vice-versa (BONDÍA, 2002). Entender o mundo contemporâneo necessita, então, pensar sobre corpo sem separá-lo do contexto em que está imerso, pois esses dois estão em constante troca.

\section{Espaço-tempo Contemporâneo}

O espaço é um conceito produzido de acordo com os sintomas de uma época e este conceito também produz e modifica a visão da sociedade (ARAúJO, 2011). Neste sentido, o conceito de espaço aqui tratado não é aquele somente sob o ponto de vista físico e geométrico, mas sim o espaço em relação com o tempo e com o conteúdo que o define, bem como com os corpos-sujeitos que com ele interagem.

Para Milton Santos (2014, p. 24 e 25), o espaço pode ser entendido como forma-conteúdo, isto é, "como uma forma que não tem existência empírica e filosófica se a considerarmos separadamente do conteúdo, e um conteúdo que não poderia existir sem a forma que o abrigou". Então, o tipo de sociedade que vive em cada lugar só é de certa maneira e tem certos costumes porque habitou certo espaço e, assim, o produziu e o produz continuamente. Isso faz com que, a cada movimento da sociedade, os lugares se criem e recriem.

Em outras palavras, o espaço é definido "como um conjunto indissociável de sistemas de objetos e de sistemas de ações" (SANTOS, 2014, p. 21). Ou seja, os objetos não existem isolados das ações que agem sobre ele e vice-versa. Esses objetos e essas ações, ainda que sejam de naturezas distintas, só podem ser vistos de certa maneira se pensados em conjunto e em relação. Essas ações são realizadas pela sociedade que interage com o 
espaço e que deve ser entendida, também, a partir desse sistema de objetos.

O tempo relaciona-se com o espaço à medida que este último é formado pelas relações sociais, além da materialidade. O tempo age sobre a matéria, assim como dá ritmo para as relações sociais, principalmente na cidade.

O império do tempo é muito grande sobre nós, mas é, sobre nós, diferentemente estabelecido. Nós, homens, não temos o mesmo comando do tempo na cidade; as firmas não o têm, assim como as instituições também não o têm. Isso quer dizer que, paralelamente a um tempo que é sucessão, temos um tempo dentro do tempo, um tempo contido no tempo, um tempo que é comandado, aí sim, pelo espaço (SANTOS, 2012).

Assim, os territórios na cidade são formados tanto pelo espaço quanto pelo tempo, bem como pelas experiências dos corpos-sujeitos. Estes, para Deleuze e Guattari (1997), encontram-se em um processo de ritornelo, que se constitui em três etapas: habita-se um território (territorialização), lança-se para fora deste mesmo território em busca de outro lugar, outros territórios (desterritorialização) e cria-se um novo território (reterritorialização).

Território, no presente estudo, é entendido a partir dos estudos pós-estruturalistas de Deleuze e Guattari, e pode ser definido tanto como um espaço vivido quanto um sistema percebido no seio do qual um sujeito se sente "em casa". É do campo do familiar e sinônimo de apropriação e subjetivação; marca as distâncias em relação a outrem e protege do caos. Ou seja, não é entendido aqui como algo fixo nem material, é individual e está em relação com o que é familiar para cada sujeito num determinado espaçotempo. Diferencia-se de "espaço" por ser da ordem do subjetivo, enquanto o conceito deste está ligado mais às relações funcionais de toda espécie (ZOURABICHVILI, 2004; HAESBAERT, 2013).

Os indivíduos buscam seus territórios. Mesmo em grandes cidades existem diversos guetos de acordo com os grupos que se identificam e procuram estabelecer-se em união num determinado território. Este território pode ser físico ou não. Para buscar o equilíbrio, "cada grupo social estaria profundamente enraizado a um 'lugar' ou a uma paisagem, com a qual particularmente se identificaria" (HAESBAERT, 2013, p. 118). O geógrafo Yu Fu Tuan (1983) define "espaço" como sendo algo em movimento, enquanto o "lugar" seria a pausa. De tal forma que podemos de- 
finir território (ou lugar) como uma parada no caos do espaço, algo que é dotado de valor por alguém em determinado tempo.

No entanto, "o ser humano contemporâneo está fundamentalmente desterritorializado" (GUATTARI, 2003, p.1), não conhece seu corpo e, consequentemente, quem é. Somos bombardeados com informações que nos atravessam, empurrados pelo capitalismo para produzir e consumir cada vez mais e, assim, nos tornamos sujeitos descontentes, em busca de algo que jamais encontraremos e, por isso, dificilmente territorializados.

A fim de compreender algo sobre esse tempo contemporâneo é necessário senti-lo, para que a apreensão venha da própria experiência. Esta necessita ser corporal, visceral, "é o que nos passa, o que nos acontece, o que nos toca" (BONDÍA, 2002, p. 21), ou seja, é o que somos capazes de perceber quando e porque estamos dispostos, é o que nos gruda, nos faz sentir e pensar sobre o que estamos sentindo.

\section{Corpo-sujeito e a Experiência}

Existem diversas formas de compreender o sujeito, dependendo do contexto em que o pensamos. Cada país, cada tempo e cada área do conhecimento o entendem de uma maneira diferente, dependendo da visão de mundo que cada um tem. Trataremos aqui das perspectivas sobre o sujeito do pós-modernismo e das relações estabelecidas entre corpo e ambiente, entendendo o corpo como corpo-espaço.

A partir da pós-modernidade, passa-se a compreender o sujeito como um território que está sempre em relação, em transformação, a partir das outras pessoas e do espaço-tempo. Entende-se o sujeito como uma entidade que se forma e se transforma a partir da relação com mundo à sua volta, na troca com a sociedade. Também no início do século XX algumas ideias em relação ao sujeito, principalmente no ocidente, começaram a ser repensadas. Ele, que muitas vezes era visto de forma dualista, com um corpo "objetificado" separado da mente, uma entidade que comandava o sujeito, vai sendo entendido de forma holística, como sujeito uno.

O raciocínio, como caminho de construção do conhecimento humano, articula-se, então, a partir da experiência prática sensível e não mais (como queria Descartes) mediante representações mentais exclusivamente pertinentes ao mundo inteligível (JESUS, 2013, p. 32). 
Por mais que o raciocínio ocorra no cérebro, só é possível que ele aconteça dentro do corpo, sendo um corpo, a partir de suas experiências sensoriais, que são nosso contato direto com o mundo. Desta forma, quanto mais os espaços por onde passamos possibilitarem experiências sensoriais diferentes, mais a experiência poderá construir raciocínios e conhecimentos novos.

Ainda assim, segundo autores como Sennett (2003), o Modernismo na Arquitetura causou um empobrecimento da experiência corporal, estética e sensorial dos indivíduos na cidade, principalmente pela ênfase dada à racionalidade. As sensações corporais foram sendo deixadas de lado gradativamente, e caminhar na cidade, por exemplo, virou hábito mecânico, uma rotina desatenta e sem experiência.

Entretanto, não é só a Arquitetura e as cidades que menosprezam o corpo e a faculdade de sentir. A cultura ocidental, em geral, entende que a "linguagem e o pensamento são fenômenos psicológicos incorpóreos e não associados ao corpo". Isso fortalece a dissociação entre corpo e mente e afasta os indivíduos de experiências sensoriais na cidade. "A arquitetura e a arte funcionam dentro dessa distância entre uma sabedoria pré-refletiva e corporificada, o conhecimento existencial e a compreensão cerebral" (PALLASMAA, 2013, p. 26 e 107).

O corpo é um dos potentes dispositivos nas relações de poder, um objeto de saber, por ser lugar de prazer e território da experiência. Por isso, ele é uma instância a qual os governos pensam dever controlar (FOUCAULT, 1988). Foucault descobre, então, esses micro-poderes que visavam a administração dos corpos e estuda os dispositivos utilizados para isso desde o século XVII. Tais dispositivos, chamados de panóplias corretoras, serviam para disciplinar os corpos "rebeldes" ou anormais nas sociedades de disciplina. São exemplos de panópticos ${ }^{1}$ as fábricas e as escolas, ou seja, espaços onde tudo está nos devidos lugares e o corpo se movimenta de uma só maneira ou o menos possível. Mas esse tipo de sociedade, segundo Foucault, está sendo substituída pelas sociedades de controle, que funcionam por comando contínuo e comunicação instantânea (DELEUZE, 1992).

Nas sociedades de disciplina não se parava de recomeçar (da escola para a fábrica, da fábrica para a caserna), enquanto nas sociedades de controle nunca se termina nada, a empresa, a formação, o serviço sendo os estados metaestáveis e coexistentes de uma mesma modulação, como que de um deformador universal (DELEUZE, 1992, p. 221 e 222).
1 Panóptico é um tipo de construção circular onde um observador central pode ver todos os pontos desse local. A princípio criado para prisões, observou-se que este tipo de espaço poderia ser utilizado em escolas e no trabalho, como meio de tornar mais eficiente o funcionamento daqueles locais, como um dispositivo disciplinador (SANT'ANNA, 2005). 
Nas sociedades de controle que hoje coexistem com as sociedades de disciplina, o panóptico não está só no espaço, já que as barreiras físicas estão dissolvidas e tudo está desintegrado. O panóptico contemporâneo está na "obrigação" de estarmos conectados a todo o momento, na corrida contra o tempo da cidade e nas câmeras que tudo veem. São dispositivos de dominação fluidos, invisíveis e móveis. A empresa, que substituiu a fábrica, coloca a rivalidade inexpiável como forma de aumentar a produção, mediante premiações para aqueles que produzem mais e, assim, também faz com que os próprios colegas monitorem uns aos outros (DELEUZE, 1992).

As sociedades de controle começaram a ser implantadas "de mansinho", com novos tipos de educação, de tratamentos, com atendimento médico a domicílio, etc. A formação educacional está cada vez mais misturada com a profissional e transforma-se em formação permanente, um controle contínuo sendo exercido sobre o operário-aluno ou o executivo-universitário. Essa ideia de liberdade, de indivíduos que não precisam estar presentes fisicamente na empresa encanta, mas também aprisiona. Todos têm um celular e têm de estar conectados a todo instante, em um trabalho aparentemente de tempo integral, que se mistura ao lazer, onde tudo é urgente, tudo é instantâneo e fugaz.

A isso Foucault chamou de Biopoder, ou seja, o controle não apenas do indivíduo a partir de seu corpo biológico, mas de um gerenciamento da vida das populações, a própria gestão da vida do corpo social. A medicina agora é preventiva, "sem médico nem doente", todos devem vacinar-se, o governo decide o que você deve fazer, para o "seu próprio bem" e todos são tratados como iguais. Esses sutis processos de governamentalização dos indivíduos fazem com que ele mesmo, por sua livre e espontânea decisão, submeta-se aos princípios da sociedade de controle e da sociedade do capital, tornando-se, assim, a presa voluntária desses processos de controle pelo mercado. "As disciplinas do corpo e as regulações da população constituem os dois polos em torno dos quais se desenvolveu a organização do poder sobre a vida" (FOUCAULT, 1988, p. 131).

O mundo passa a ser digital, as cidades também, assim como o trabalho. A arte agora é também audiovisual - depende de um computador. Ela também vai para a rua, em busca do público que não tem mais tempo de ir ao teatro. Trabalho e lazer misturam-se. Cenas cotidianamente contemporâneas: enquanto se caminha se assiste a uma obra de dança, no metrô; 
indo para casa, se ouve um músico de rua; quando se chega à estação, vemos obras audiovisuais. Todavia, a competição e a manutenção do individualismo, cada vez maior por parte dos cidadãos, causa a dificuldade da relação com o diverso. As pessoas, na sua rotina inalterada, cada vez menos olham para o lado, estão impregnadas do trabalho e

se mostram indignadas com o fazer artístico, por este não ter caráter produtivo. Revelam, assim, o incômodo com sua própria situação de sujeitado pelo sistema no momento em que verbalmente propõe a aguda agressividade com os artistas, que lhes parecem "vagabundos" (ILDEFONSO, 2012, p. 83).

De tal modo, nós mesmos reprimimos o outro no seu fazer improdutivo, pois não há alteridade, todos têm de ser iguais. Se eu trabalho tantas horas por dia para ter uma vida "digna" - dignidade esta que o capitalismo nos impõe - como o outro está se divertindo na rua na minha frente? No horário em que todos deviam estar "trabalhando"?

De qualquer forma, nossos corpos-sujeitos estão sempre em ritornelo, em reterritorialização a partir da cultura, da arte de rua, dos espaços e da sociedade com que trocamos. As cidades exercem um grande poder sobre nós e quando são, por exemplo, projetadas privilegiando os automóveis em detrimento dos pedestres, intervêm diretamente na saúde e nos hábitos de seus habitantes dificultando a possibilidade de diferentes experiências sensoriais entre o corpo e a cidade.

\footnotetext{
atualmente, as infinitas conexões, desorganizações e transgressões entre corpo interno-externo e mesmo entre corpo orgânico-artificial vieram desestabilizar ainda mais o conceito de corpo, que velozmente parece deixar de ser um corpo próprio para se tornar um corpo-espaço em eterno vir a ser (MIRANDA, 2008, p. 26).
}

No entanto, falar de corpo sem falar do meio em que ele se encontra não faz sentido, pois ambos são considerados codependentes (KATZ; GREINER, 2002). Somos nossos corpos, que são o ambiente em que vivemos, somos as relações que fazemos com tudo que está à nossa volta. Além do ambiente físico, os grupos sociais em que vivemos também nos transformam, como por exemplo, a escola, a igreja, entre outros. E as transformações também ocorrem no espaço, visto que os corpos modificam os espaços a partir da sua interação com eles: "O corpo se metamorfoseia nos espaços que ocupa e assim transforma o ambiente em um movimento de mão dupla" (GREINER, 2010, p. 127). 


\section{Corpo-Espaço}

Então, falaremos de corpo-espaço pensando na Banda ou Faixa de Moebius como a materialização desse conceito contemporâneo de fluidez. "A faixa de Moebius é a mais elementar superfície não-orientável; e tem como característica ter apenas uma única e contínua margem" (SPERLING, 2003, p. 141), de maneira que a mesma superfície transforma-se a partir da relação que estabelecemos com ela de dentro e fora. "Pode-se ter a ilusão de que há diversas faces, porém consiste em uma só face. A comprovação é se tentarmos traçar uma linha a partir de qualquer ponto ao longo da fita, ela se encontrará com o seu início" (BARROS, 2011, p. 39).

A partir da figura 1, relacionamos corpo e espaço como duas entidades que estão em constante troca. Paola Jacques e Fabiana Britto criaram o conceito de "corpografia urbana", relacionando dança e urbanismo. Regina Miranda nos falou sobre Corpo-Espaço e Takahashi buscou compreender o espaço a partir da perspectiva dos sujeitos. Já Katz e Greiner explicam a cultura como um produto do meio, a ponte entre interior e exterior.

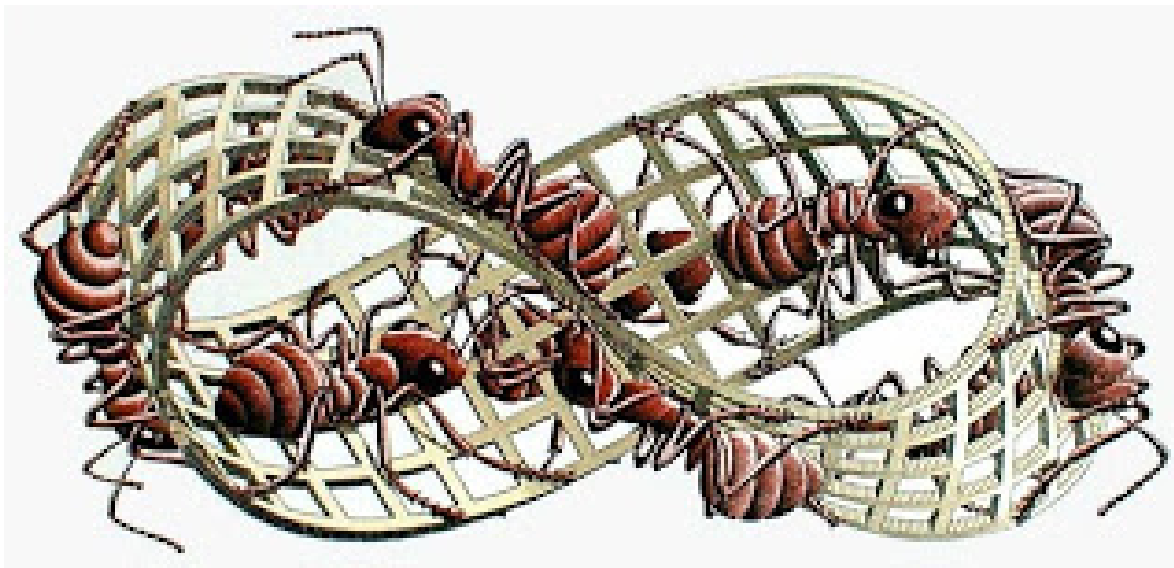

Figura 01

Banda de Moebius.

Fonte: MATEMÁTICA CURIOSA. Acesso em: 24/mar/2017

É possível compreender o espaço a partir da mesma relação da Faixa de Moebius, já que o conjunto de fixos e fluxos, que Milton Santos (2014) propõe, se confunde e redefine cada lugar.

Os elementos fixos, fixados em cada lugar, permitem ações que modificam o próprio lugar, fluxos novos ou renovados que recriam as condições ambientais e as condições sociais e redefinem cada lugar. Os fluxos são um resultado direto ou indireto das ações e atravessam ou se instalam nos fixos, modificando a sua significação e o seu valor, ao mesmo tempo em que também se modificam (SANTOS, 2014, p. 61 e 62). 
Assim, os fixos, que seriam os objetos e os fluxos, que seriam os sujeitos na cidade, estão confundidos e misturados e a rua, o espaço, a arquitetura fazem parte do corpo dos habitantes que por ali passam. Essa relação pode ser entendida por "Corpografia Urbana", um conceito que se afasta da ideia de cidade como um lugar em que o corpo se insere e a entende "como um campo de processos em que o corpo está coimplicado" (BRITTO, 2013, p. 37), ou seja, o espaço não é um vazio, está sempre em troca com o corpo que interage com ele.

A "corpografia urbana" é conceituada como uma cartografia corporal,

ou seja, parte da hipótese de que a experiência urbana fica inscrita, em diversas escalas de temporalidade, no próprio corpo daquele que a experimenta, e dessa forma também o define, mesmo que involuntariamente (JACQUES, 2008, s.p.).

Tal concepção está relacionada ao conceito de "Corpo-Espaço" de Miranda (2008, p. 24), que implica na fluidez das fronteiras corporais e do espaço. A autora compreende o movimento, o corpo e o espaço "permanentemente imersos em mútuas relações de transformação", como Jacques (2008), que não entende o corpo separado da cidade. A "corpografia urbana" sugere, então, que o corpo e a cidade configuram-se mutuamente; assim, a cidade fica inscrita nos corpos que interagem com ela, passando a ser também aqueles sujeitos: "somos a cidade que experienciamos".

Para Takahashi (2010), o espaço não existe por si só, mas pode ser compreendido a partir da perspectiva do sujeito que o observa. E nessa relação, o observador não é passivo, já que, de acordo com o princípio da incerteza de Heisenberg ${ }^{2}$, o simples ato de observação de um átomo já altera suas condições. Devido a isso, no momento da observação, o sujeito passa a ser interagente, transformador daquele espaço.

Ainda assim, "o corpo foi esquecido nos dogmas urbanísticos dos anos 90, saturado pelas coordenadas funcionais da cidade e sufocado pelos sistemas de tráfego e circulação" (TAKAHASHI, 2010, p. 145). Comunicamo-nos pelo corpo, tudo o que sentimos e pensamos é transmitido pelo corpo e essa relação se dá principalmente nos espaços públicos, na cidade. Contudo, vivemos no ciberespaço ${ }^{3}$, onde esquecemos que somos corpo e diminuímos nossas relações sinestésicas com outros sujeitos.
2 o princípio da incerteza de Heisenberg consiste num enunciado da mecânica quântica, formulado inicialmente em 1927, por Werner Heisenberg, impondo restrições à precisão com que se podem efetuar medidas simultâneas de uma classe de pares de observáveis em nível subatômico.

3 Ciberespaço é um espaço virtual, não-material, onde é possível relacionar-se e comunicar-se com outras pessoas sem a presença física de cada um. Se dá através da internet, de celulares e diversos outros aparelhos de comunicação. 
As cidades contemporâneas estão sendo planejadas de forma espetacular, distanciando os sujeitos do espaço urbano, com projetos que "buscam transformar os espaços públicos em cenários, espaços desencarnados, fachadas sem corpo: pura imagem publicitária" (JACQUES, 2010, p. 108). E a redução de seu uso afeta as dinâmicas sociais cotidianas, diminuindo a participação cidadã e a experiência corporal de apreensão da cidade. Dessa forma, a utilização da cidade de forma ativa pode influenciar significativamente na educação do sensível, possibilitando aos cidadãos a descoberta de seus corpos, sendo capazes de resistir ao corpomercadoria 4 .

se a cidade é o mundo criado pelo homem, segue-se que também é o mundo em que ele está condenado a viver. Assim, indiretamente e sem nenhuma consciência bem definida da natureza de sua tarefa, ao criar a cidade o homem recriou a si mesmo (PARK apud HARVEY, 2014, p. 28).

O tipo de cidade em que queremos viver está diretamente relacionado ao tipo de pessoas que queremos ser e aos tipos de relações que buscamos com o outro. "O direito à cidade é, portanto, [...] um direito de mudar e reinventar a cidade mais de acordo com nossos mais profundos desejos." (HARVEY, 2014, p. 28). A luta por uma cidade mais sensível, onde se tenha espaço para a arte de rua, para os encontros é, também, uma luta por um ser humano mais sensível, menos automatizado, menos ligado à produção de capital uma revolução interna contra o sistema que nós próprios construímos e no qual ficamos enredados. Uma revolução contra as pessoas que nos tornamos e que não conhecemos mais, contra essas máquinas humanas atrás de smartphones, com muita informação e pouca experiência.

\section{Cidade-mercado e Rua}

Quando falamos em "cidade" pensamos em ocupação compacta do solo, em populações culturalmente mistas e num acúmulo de culturas e funções diversas num único lugar que irradia um alto grau de centralidade atrativa (PRIGGE, 2002, p. 51).

Algumas características de cidade estão configuradas desde 2.500 a.C. A conformação de rua, quarteirão de casas, mercado, recinto religioso e administrativo ainda é a forma como imaginamos as cidades, apesar de sua transformação natural (ARAÚJO, 2010). Harvey (2014) observa que "a cidade é o lugar onde pessoas de todos os tipos e classes se misturam, ainda que relutante e conflituosamente, para produzir uma vida em comum, embora perpetuamente mutável e transitória" (p. 134). Por isso, a cidade também é lugar da
${ }^{4}$ Corpo-mercadoria é o corpo como objeto de consumo, para o qual se pensam produtos para a venda, ignorando o sujeito que é aquele corpo (JACQUES, 2008). 
5 Aquele que escapa, resiste, vive e sobrevive no cotidiano dessa outra urbanidade, através de táticas de resistência e apropriação do espaço urbano, de forma anônima (ou não) e dissensual, radical. Esse "outro urbano" se explicita através da figura do morador de rua, ambulante, camelô, catador, prostituta, artista, entre outros (JACQUES, 2012).

6 Georges-Eugène Haussmann (Paris, 1809 - 1891) foi responsável pela reforma urbana de Paris que modificou expressivamente a cidade, abrindo grandes avenidas e bulevares. política, é lugar de luta de classes, onde os desejos dos diversos grupos de seus habitantes se mostram. Entretanto, o ser humano, que busca estar sempre territorializado, não quer o encontro com o diferente, com o que não Ihe é familiar. 0 encontro com o "outro urbano" 5 é uma forma de desterritorialização dos cidadãos que passam na rua e, por isso, muitos não se sentem à vontade.

As cidades são fenômenos de classe, pois elas "surgiram da concentração geográfica e social de um excedente de produção" (HARVEY, 2014, p. 30). Isso significa que quando existe excedente, existe alguém ou alguma instância que controla o uso do lucro desse acúmulo, que está nas mãos de poucos de acordo com uma política do capitalismo neoliberal. Assim, para pensar em reforma urbana, em formas alternativas de urbanização, é preciso pensar em alternativas anticapitalistas.

As cidades poderiam vir a ser transformadas para o recebimento/escoamento dessa mercadoria excedente, através da construção de estradas, ferrovias, portos. Na cidade de Paris, em 1853, por exemplo, os projetos e construções de obras públicas encabeçadas por Haussmann ${ }^{6}$, foram instrumentos de estabilização social, pois essas transformações urbanas fizeram com que a cidade absorvesse imensas quantidades de mão de obra e capital. Depois disso, Paris transformou-se na "Cidade Luz", o maior centro de consumo, turismo e prazeres, criando um novo estilo de vida urbano e, consequentemente, um novo tipo de "persona" urbana (HARVEY, 2014), já que, como vimos, corpo e espaço, sujeito e cidade se retroalimentam.

Mas a luta política pelo "direito à cidade" equivale a reivindicar por algo que não mais existe, já que a oposição urbano-rural está desaparecendo: "além do mais, o direito à cidade é um significante vazio. Tudo depende de quem the vai conferir significado" (HARVEY, 2014, p. 19 e 20). A cidade pode ser entendida como um fenômeno cultural porque ela é o espaço que reúne diversidades, tendo em vista a ideia de centralidade, aproximação, reunião, enfim, local de relações. Assim como também é lugar de conflitos, pois há tensão entre os diferentes. Mas essa tensão, segundo Jacques (2010), é capaz de transformar e de possibilitar a criação, ou seja, proporcionar modificações tanto nas cidades quanto nas culturas, a partir de negociações entre os seres humanos e as cidades, entre as culturas e os espaços.

Cada época tem seu padrão de civilidade, que é transformado a partir do comportamento das pessoas e das 
mudanças que ocorrem no espaço, bem como os conceitos de cidade que também se modificam no tempo. "De qualquer forma, esse 'estar de acordo' não está dado como um padrão social conhecido; pelo contrário, ele é construído o tempo todo em um processo permanente de negociação" (REYES, 2005, p. 22). Ou seja, é preciso padrões pré-estabelecidos para que se possa conviver na aglomeração chamada cidade.

Na contemporaneidade, "cidade" está menos ligada às questões físicas e geométricas, já que, estando conectado, qualquer ser humano pode participar da cidade mundial: "a cidade passa a ser definida a partir de diferentes parâmetros, tais como finanças, capacidade informacional e de conexão planetária, nós e redes, densidade demográfica, virtualização, experiência sensorial etc." (ARAúJO, 2011, p. 48). No entanto, os arquitetos, os urbanistas e os planejadores do espaço urbano ainda têm grande influência no tipo de cidade que é construída, visto que a concepção de arquitetura e urbanismo está estreitamente ligada à concepção de espaço.

É certeza que as separações e os divórcios, a violência familiar, o excesso de canais a cabo, a falta de comunicação, a falta de desejo, a apatia, a depressão, os suicídios, as neuroses, os ataques de pânico, a obesidade, a tensão muscular, a insegurança, a hipocondria, o estresse e o sedentarismo são culpa dos arquitetos e incorporadores (Medianeras, 2011).

Gustavo Taretto, diretor de Medianeras, logo no início do filme provoca o espectador com algumas características acerca da contemporaneidade na urbe: a preferência do certo ao não-saber; a linha reta às linhas curvas; as menores distâncias; o transporte mais veloz; a preferência a tudo o que nos der menos possibilidade de sentir, uma vez que a cidade contemporânea tem perdido sua finalidade humana, tendo progredido apenas materialmente. A crítica do filme é a de que a humanidade contemporânea simplesmente (sobre) vive na cidade, sem questionar-se. "Se as pessoas não sabem aonde vão, o capital Ihes oferece metas às quais deverão dirigir-se" (NEGT, 2002, p. 18).

A principal mensagem de Medianeras é a necessidade de se viver o instante, descobrir as surpresas, enxergar o que está bem diante de nosso nariz: a existente falta de humanidade e a emergente possibilidade dela. Precisamos apostar na descoberta sensível sobre o que nos enfraquece e o que nos potencializa na experiência com a cidade contemporânea. Na figura 2 (cenas do filme Medianeras), as personagens Martín e Mariana resolvem abrir janelas nas fachadas cegas 
de seus apartamentos. É neste momento que os dois olham-se e encontram-se. Estavam a todo o momento um ao lado do outro, mas é com uma micropolítica, com um movimento mínimo em meio ao turbilhão de movimentos de construção e reconstrução da cidade, que o casal se forma.
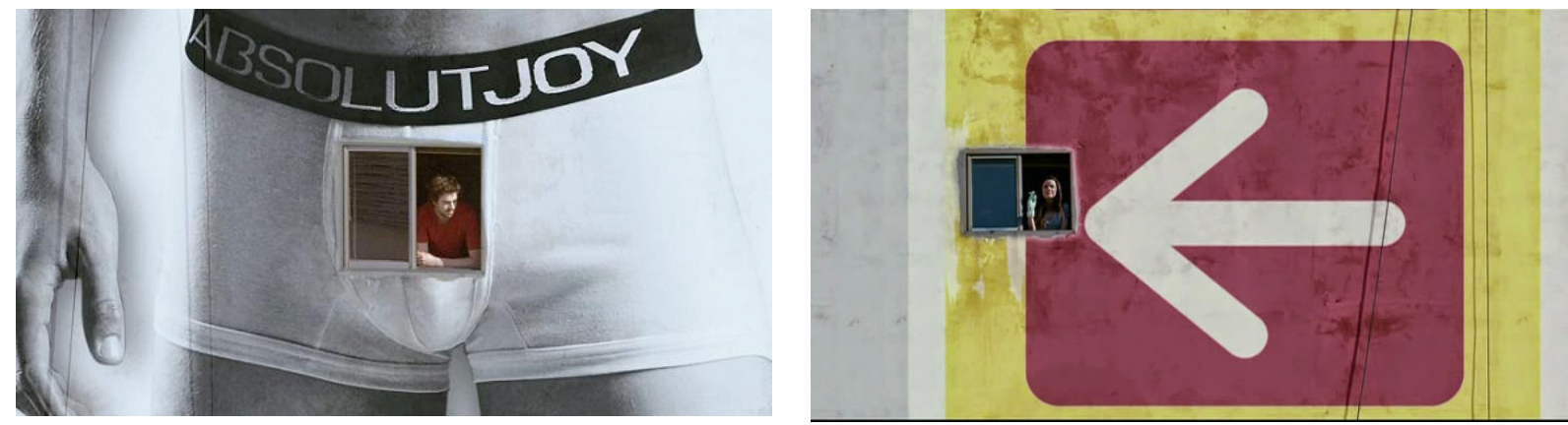

Figura 02

Cena do filme "Medianeras".

Fonte: REVIDE. Acesso em: 24/mar/2017

Todavia, sob a lógica da produção capitalista, a cidade hoje, lotada de shoppings e condomínios fechados, nega a ideia de centralidade e traz a noção de segregação. O espaço urbano possui sua dinâmica imposta pelo capital, por isso a luta pelo direito à cidade é uma luta anticapitalista, é uma luta pelo direito do uso comum por parte de todos, da classe mais alta à mais baixa, mas as grandes empreiteiras seguem fragmentando a cidade, acabando com o comum. "A urbanização capitalista tende perpetuamente a destruir a cidade como um comum social, político e habitável" (HARVEY, 2014, p. 156).

Essa falta de uso do espaço público despolitiza a cidade, pois é no dissenso, segundo Rancière (2005), que está o cerne da política. Para ele, um lugar onde falta política é um lugar em que sobra polícia, onde se visa excluir tudo o que é diferente e regular a ordem. A política é "a possibilidade de opor um mundo comum ao outro" (RANCIÈRE, 2005, s.p.). Assim, para existir política é preciso existir o encontro com o diferente, com aquele que pensa e age diferente de nós.

Hoje em dia, ordem significa justamente falta de contato. (...) A massa de corpos que antes se aglomerava nos centros urbanos hoje está dispersa, reunindo-se em polos comerciais, mais preocupada em consumir do que com qualquer outro propósito mais complexo, político ou comunitário. Presentemente, a multidão sente-se ameaçada pela presença de outros seres humanos que destoam de suas intenções (SENNETT, 2003, p. 19 e 20).

Essa despolitização do espaço público também causa e é causada pela mercantilização da cidade. "A quali- 
dade da vida urbana tornou-se uma mercadoria para os que têm dinheiro" (HARVEY, 2014, p. 46). Os que têm capacidade financeira para comprar "um pedaço de cidade" o fazem e têm nas mãos uma mercadoria, fazendo de tudo para obter lucros com seu "bem imóvel". Venda! Negócios! Mídia! E ainda são capazes de ser a propaganda da cidade: "Temos o prédio mais alto do mundo!". Turismo, dinheiro, espetáculo, máscaras... e a cidade vira cidade-museu.

Tanto a cultura quanto a cidade passaram a ser consideradas como mercadorias estratégicas, manipuladas como imagens de marca, principalmente dentro do atual processo de globalização da economia (JACQUES, 2010, p. 164).

Então, cultura se produz, se reproduz e se vende. Assim como se vende a cidade. Enfim, "a mercantilização e comercialização de tudo constitui uma das marcas características de nossa época". Essa cidade como "marca", como produto cultural, comporta certos tipos de pessoas e coisas, ao passo que exclui aqueles que não se encaixam, não se adequam àquela marca criada (HARVEY, 2014, p. 202). As cidades, ao invés de serem lugares do encontro e da reunião dos diferentes, são lugares do turismo, do consumo, do espetáculo. A globalização hegemoniza as cidades e generaliza seus habitantes: "se perdeu o gosto pela diferença, pelo imprevisto, pelo acontecimento singular" (GUATTARI, 2003, p. 1).

O capitalismo leva ao individualismo e "os indivíduos sentem-se apenas usuários da cidade" (PRIGGE, 2002, p. 53), ou seja, não se comprometem com a manutenção da política urbana. Como mencionado anteriormente, um dos elementos que auxiliou no desenvolvimento do capitalismo foi o que Foucault (1988) denominou como biopoder, pois garantiu ao Estado o controle dos corpos no aparelho de produção. Shoppings e condomínios fechados funcionam como falsos espaços públicos e sua multiplicação faz com que a população diminua sua participação e interação com a cidade "realmente pública". Por outro lado, existem os que vivem a cidade de outra forma, que fazem micropolítica, como as personagens Mariana e Martín. Estes transformam os lugares mesmo de dentro do sistema capitalista-espetacular.

As duas principais personagens do filme, que se passa em Buenos Aires, vivem trancadas em seus apartamentos, sedentários e depressivos, e só se jogam no caos do espaço urbano em situações extremamente necessárias. Apesar disso, Mariana procura constantemente o "Wally7 na cidade" (figura 3) e Martín vive em salas de bate-papo virtuais. O que eles buscam? O encontro com o outro, o sentir, o humano.
7 "Onde está Wally?" é uma série de livros de caráter infanto-juvenil criada pelo ilustrador britânico Martin Handford, baseada em ilustrações e pequenos textos. O livro tem ilustrações que ocupam duas páginas inteiras, nas quais em algum lugar está escondido Wally e o leitor tem de achá-lo. 
É no encontro face a face que temos a apreensão do outro na sua quase total plenitude, pelo menos no que diz respeito a seus sinais exteriores. Todos os sentidos estão aí disponíveis à percepção do outro (REYES, 2005, p. 21).

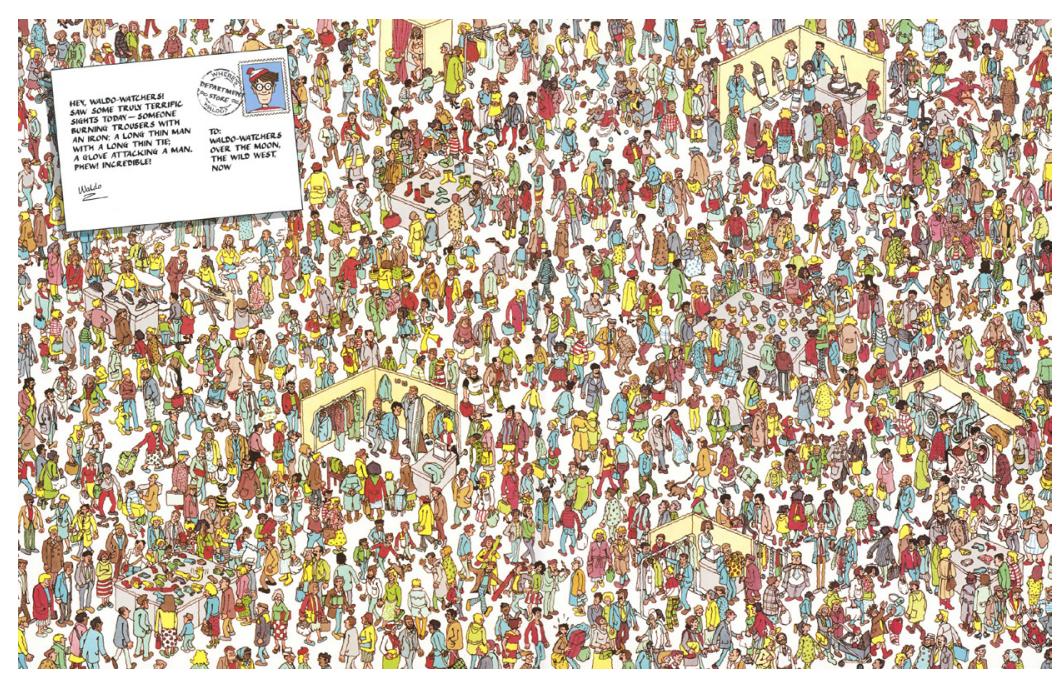

Figura 03

Ilustração do livro "Procurando Wally".

Fonte: MARINA FRANCONETI. Acesso em: 24/mar/2017

A velocidade das transformações no modo de viver não acompanhou a (falta de) velocidade da sensibilidade humana. Martín e Mariana buscam o sentir, e é quando eles abrem janelas - literalmente - para a rua, que isso acontece. Estão fazendo micropolítica. Não é nos bate-papos na internet ou nas redes sociais que o encontro acontece, é na cidade. Um paradoxo: vivemos escondidos na multidão de habitantes das cidades, diluindo nossos corpos no meio de outros anônimos, somos "Wallys" no espaço urbano. Esses corpos tão próximos e ao mesmo tempo tão distantes "diluem a identidade e a autonomia" (TAKAHASHI, 2010, p. 138), assim, nos misturamos com os outros, somos os outros, ao mesmo tempo em que as possibilidades de experiência com o outro não são possíveis. Tornamo-nos sujeitos anestesiados.

As novas tecnologias (telefone, computador, internet), os ambientes virtuais, os novos meios de transporte (público, privado, individual, coletivo, veloz ou mais veloz ainda), as novas formas de comer, trabalhar, habitar e amar influenciaram e continuam influenciando significativamente nas cidades e nos sujeitos que as produzem ao passo em que são produzidos por elas.

"A experiência é cada vez mais rara por excesso de trabalho" (BONDÍA, 2002, p. 23). Viramos mecânicos depois da Revolução Industrial, funcionamos como máquinas. A cultura de massas proporciona aos indi- 
víduos uma multiplicidade de estímulos e sensações, mas estas sensações não se transformam em experiência porque o tempo é da velocidade e experimentar algo "requer um gesto de interrupção, um gesto que é quase impossível nos tempos que correm: requer parar para pensar, parar para olhar, parar para escutar [...]" (BONDÍA, 2002, p. 24).

\section{Abrindo Brechas nas Medianeras}

Desta forma, para possibilitar viver experiências ativas, temos que desligar o automático e ligar o manual, o braçal, o corporal. Precisamos compreender que o ócio é necessário, precisamos nos dar tempo para sentir, para nos tornar humanos de novo e isso requer aprendermos a lentidão.

As cidades são importantes espaços de subjetivação e devem ser pensadas como tal - espaços de liberdade, de criação, de arte, comandadas pelas pessoas, ao invés de pelo mercado imobiliário. $E$, para produzir espaços de liberdade, é preciso que as cidades sejam pensadas por diversas áreas do conhecimento, de forma cada vez mais democrática, para que todos tenham o direito à cidade, cada qual à sua maneira, diversas cidades em uma.

Vê-se nos espaços públicos uma possibilidade de construção do conhecimento através da experiência do corpo na cidade, assim, esses espaços necessitam ser pensados a fim de proporcionar múltiplas sensações aos sujeitos que ali convivem. Nesse sentido, a diversidade de atividades no espaço público, que proporcionam diferentes experiências estéticas e corporais à rotina de caminhar pela cidade, pode ocorrer tanto através da arquitetura do próprio espaço, como também através das atividades que não estão programadas, como as intervenções urbanas, os vendedores ambulantes e as manifestações políticas que utilizam a cidade como espaço realmente público. 


\section{Referências}

ARAÚJO, Rosane Azevedo de. A cidade sou eu. Rio de Janeiro: Novamente, 2011.

ARAÚjO, Ubiratan Castro de. As cidades e suas contradições. In: ROCHA, Renata; RUBIM, Antonio Albino Canelas (Orgs.). Políticas Culturais para as Cidades. Salvador: EDUFBA, 2010.

BARROS, Carolina M. F. de. Dobrando a Arquitetura Contemporânea: um estudo sobre a obra de Peter Eisenman e o uso do conceito de dobra. Dissertação. Faculdade de Arquitetura e Urbanismo. Programa de Pós-graduação em Arquitetura e Urbanismo. Universidade Federal de Pelotas. Pelotas, RS: UFPel, 2011.

BONDÍA, Jorge Larrosa. Notas sobre a experiência e o saber de experiência. Rev. Bras. Educ. [online]. 2002, n.19, pp. 20-28.

BRITTO, Fabiana Dultra. A ideia de Corpografia Urbana como pista de análise. Redobra, Salvador, EDUFBA, $\mathrm{n}^{\circ}$ 12, ano 4, 2013.

DELEUZE, Gilles. Conversações: 1972-1990. Trad. Peter Pál Perbart. São Paulo: Ed. 34, 1992.

DELEUZE, Gilles e GUATTARI, Félix. Mil Platôs: capitalismo e esquizofrenia. V.4. São Paulo: Ed. 34, 1997.

FOUCAULT, Michel. História da Sexualidade I: A vontade de Saber. Trad. Maria Thereza Albuquerque e J. A. Guilhon Albuquerque. Rio de Janeiro, Edições Graal, 1988.

GUATTARI, F. Prácticas Ecosóficas y Restauración de la Ciudad Subjetiva. In: Quaderns d'arquitectura i urbanisme, no 238. Ed. Reunidas SA / GRUPO ZETA, Barcelona, 2003.

HAESBAERT, Rogério. Territórios Alternativos. 3 ed. São Paulo: Contexto, 2013.

HARVEY, David. Cidades Rebeldes: do direito à cidade à revolução urbana. Trad. Jeferson Camargo. São Paulo: Martins Fontes, 2014.

ILDEFONSO, Élder Sereni. Estudos Cênicos Híbridos e o Corpo em [Des]Territorialização no Processo de Urbanização. Dissertação de Mestrado Programa de Pós-graduação em Artes da Universidade Estadual Paulista. São Paulo: UNESP, 2012.

JACQUES, Paola Berenstein. Corpografias urbanas. 2008. Disponível em: http://www.vitruvius.com.br/revistas/read/arquitextos/08.093/165. Acesso em: 23/05/14.

JACQUES, Paola Berenstein. Notas sobre Cidade e Cultura. In: ROCHA, Renata; RUBIM, Antonio Albino Canelas (Orgs.). Políticas Culturais para as Cidades. Salvador: EDUFBA, 2010.

JESUS, Thiago Silva de Amorim. Corpo, Ritual, Pelotas e o Carnaval: uma análise dos desfiles de rua entre 2008 e 2013. Tese do Curso de Doutorado em Ciências da Linguagem da Universidade do Sul de Santa Catarina. Palhoça, SC: UNISUL, 2013

KATZ, Helena; GREINER, Christine. A natureza cultural do corpo. In: SOTER, Silvia; PEREIRA, Roberto (Orgs.) Lições de Dança 3. Rio de Janeiro: UniverCidade Editora, 2002.

MATEMÁTICA CURIOSA. Disponível em: http://matcuriosa.blogspot.com.br/2009/05/faixa-de-moebius.html. Acesso em: 24/mar/2017.

MARINA FRANCONETI. Disponível em: https://marinafranconeti.wordpress.com/tag/medianeras/. Acesso em: 24/mar/2017. 
MEDIANERAS: Buenos Aires na Era do Amor Virtual. Direção: Gustavo Taretto. Buenos Aires: Rizoma, 2011. 95 minutos. Disponível em: https://www.youtube.com/watch?v=8javEbiY1c. Acesso em: 17 set. 2014.

MIRANDA, Regina. Corpo-espaço: aspectos de uma geofilosofia do movimento. Rio de Janeiro: 7Letras, 2008.

NEGT, Oskar. Espaço Público e Experiência. In: PALLAMIN, Vera M. (Org.). Cidade e Cultura: esfera pública e transformação urbana. São Paulo: Estação Liberdade, 2002.

PALLASMAA, Juhani. A imagem corporificada: imaginação e imaginário na arquitetura. Porto Alegre: Bookman, 2013.

PRIGGE, Walter. Metropolização. In: PALLAMIN, Vera M. (Org.). Cidade e Cultura: esfera pública e transformação urbana. São Paulo: Estação Liberdade, 2002.

RANCIÈRE, Jacques. A partilha do sensível: estética e política. São Paulo: EXO experimental org./ Editora 34, 2005.

REVIDE. Disponível em: http://revide.blogspot.com.br/2014/05/revendo-medianeras. html. Acesso em: 24/mar/2017.

REYES, Paulo. Quando a rua vira Corpo [ou a dimensão pública na ordem digital]. Editora Unisinos: São Leopoldo, 2005.

SANTOS, Milton. A Natureza do Espaço: Técnica e Tempo, Razão e Emoção. 4 ed. São Paulo: Editora da Universidade de São Paulo, 2014.

SANTOS, Milton. O Tempo nas Cidades. In: Revista Ciência e Cultura, São Paulo, vol. 54, n. 2, 2012. [online] Disponível em: <http://cienciaecultura.bvs.br/scielo.php?pid=S0009-67252002000200020\&script=sci_arttext>. Acesso em: 09 Abr. 2015.

SENNETT, Richard. Carne e Pedra: O corpo e a cidade na civilização ocidental. Trad. Marcos Aarão Reis. 3 ed. Rio de Janeiro: Records, 2003.

SPERLING, David Moreno. Arquiteturas Contínuas e Topologia: similaridades em processo. Dissertação de Mestrado do Programa de Pós-graduação em Tecnologia do Ambiente Construído. São Carlos: Escola de Engenharia de São Carlos, Universidade de São Paulo, 2003.

TAKAHASHI, Jo. Dimensões do corpo contemporâneo. In: GREINER, Christine; AMORIM, Cláudia (Orgs.). Leituras do corpo. 2 ed. São Paulo: Annablume, 2010.

TUAN, Yu Fu. Espaço \& lugar. São Paulo: DIFEL, 1983.

ZOURABICHVILI, François. O Vocabulário de Deleuze. Trad. André Telles. Rio de Janeiro: Relume Dumara, 2004. 